\title{
Jogos tradicionais portugueses adaptados e dinâmicas intergeracionais em pessoas com doença de Parkinson
}

\section{Adapted traditional games and intergenerational strategies in people with Parkinson's disease}

\author{
Marlene Rosa (1,2) \\ Carina Gomes Forte (1) \\ Raul Antunes (1,3) \\ Tânia Maurício (4) \\ (1) Inst Polit Leiria, Esc Sup Saúde, Portugal \\ (2) Inst Polit Leiria, ciTechCare, Portugal \\ (3) Esc Sup Ciênc Soci Educ, CIEQV, Portugal \\ (4) Ass Port D Parkinson, Leiria, Portugal
}

Recebido: 28/12/2019; Revisto: 04/03/2020; Aceite: 10/05/2020.

https://doi.org/10.31211/rpics.2020.6.1.163

\begin{abstract}
Resumo
Contexto e Objetivo: Tendo em conta as limitações na terapia convencional, os jogos são cada vez mais utilizados pelo seu potencial em integrar as várias dimensões humanas afetadas pela Doença de Parkinson. Este estudo teve como objetivo testar a aplicação de um programa de jogos tradicionais adaptados a pessoas com DP, incluindo dinâmicas intergeracionais. Métodos: Foram realizadas três sessões de jogos tradicionais adaptados, incluindo nove pessoas com Doença de Parkinson. Foi ainda dinamizada uma sessão com dinâmicas intergeracionais, precedida de uma sessão educativa às crianças (pré-escolar, 4 e 5 anos de idade) sobre o tema do envelhecimento. Deste modo, antes e após cada sessão, foi avaliado o nível de autoeficácia através da Escala de Autoeficácia para a Atividade com Sentido de cada participante, bem como o feedback dos participantes e das crianças através de uma entrevista estruturada. A análise da entrevista implicou a codificação usando a Classificação Internacional de Funcionalidade, Incapacidade e Saúde por dois investigadores independentes. Resultados: Ao longo das sessões observou-se que cerca de $50 \%$ dos participantes melhoraram relativamente ao nível da autoeficácia e os restantes 50\% mantiveram a cotação máxima. Observou-se também a importância da sessão educativa às crianças onde se verificou uma melhoria no nível de aprendizagem sobre o tema de envelhecimento, melhorando "o domínio de adaptações dos jogos para idosos", bem como "o saber ajudar durante a implementação dos jogos "em população idosa. Ainda no decorrer das sessões, as pessoas com Doença de Parkinson assinalaram a importância de temas como: a componente afetiva que advêm da experiência, as memórias, o relacionamento entre os participantes e as crianças. Conclusões: Este estudo permitiu verificar que os jogos tradicionais adaptados têm impacto no nível da autoeficácia dos participantes bem como são catalisadores de dinâmicas positivas entre várias gerações.
\end{abstract}

Palavras-Chave: Doença degenerativa; Terapia recreativa; Idoso; Criança pré-escolar.

\section{DI\&D | ISMT}

rpics@ismt.pt

https://rpics.ismt.pt
Publicação em Acesso Aberto

(C)2020. O(s) Autor(es). Este é um artigo de acesso aberto distribuído sob a Licença Creative Commons Attribution, que permite uso, distribuição e reprodução sem restrições em qualquer meio, desde que o trabalho original seja devidamente citado.
Marlene Rosa

IPL

R. de Santo André 2410, Leiria, Portugal

Tel. 351968918915

Email: marlene.rosa@ipleiria.pt 


\begin{abstract}
Background and Aim: Conventional rehabilitation treatment processes demonstrate several limitations; therefore, games have been increasingly used because of their potential to integrate the multidimensional components affected by Parkinson's disease. This study aims to test the application of a traditional game program adapted to people with PD, including intergenerational dynamics. Method: Three sessions were held with adapted traditional games, including nine older adults with Parkinson's Disease. Additionally, a session with intergenerational dynamics was also organized, preceded by an educational session for children about the aging process. Thus, before and after each session, the level of self-efficacy was assessed using the Sense of Activity Self-Efficacy Scale, as well as collecting feedback from participants and children using a structured interview. The analysis of this interview involved the International Classification of Functioning, Disability, and Health coded by two independent investigators. Results: Throughout the games' sessions, it was observed that about $50 \%$ of participants improved regarding their self-efficacy level, and the remaining 50\% maintained the maximum rating. It was also noted the importance of the educational session for children where there was an improvement in the level of learning, reaching specific areas such as: "learning adaptations of games for the elderly," as well as the "importance of children's support on games' implementation session." Also, during the sessions, people with Parkinson's Disease pointed out the importance of themes such as the affective component that comes out from this experience, memories, the relationships between participants and children. Conclusions: This study showed that traditional games with adapted instructions have an impact on the participants' self-efficacy level and were a stimulus for positive dynamics across generations.
\end{abstract}

Keywords: Neurodegenerative disease; Recreation therapy; Older adult; Preschool child.

\title{
Introdução
}

A doença de Parkinson (DP) é caracterizada por um distúrbio do movimento caracterizado por sintomas motores parkinsonianos clássicos, tais como a bradicinesia, rigidez muscular, tremor em repouso e comprometimento postural e da marcha (Kalia \& Lang, 2015). Para além das alterações motoras em pessoas portadoras da DP, pode também existir um comprometimento cognitivo, que inclui défices executivos no planeamento, bem como alterações de memória e de atenção. Porém, as características cognitivas da DP são diversas e variam entre pessoas (Robbins \& Cools, 2014). Por exemplo, características tais como a perceção, associação, memória, raciocínio e linguagem, podem influenciar significativamente os processos executivos no planeamento (Koerts et al., 2011).

Uma das mais significativas dificuldades no processo de reabilitação da pessoa com DP consiste no desenho de programas que integrem as várias dimensões afetadas por esta doença, o que conduz a resultados pouco satisfatórios para os pacientes e a uma diminuição consequente da sua autoeficácia. Por autoeficácia, entendese o julgamento da capacidade pessoal que influencia a escolha das atividades e da motivação da pessoa. Quando o sentimento da autoeficácia está diminuído, o estabelecimento de metas, a perseverança e a definição de expectativas são processos difíceis. Consequentemente, a autoeficácia de um individuo com DP é uma componente importante que deve avaliada e reconhecida num tratamento de reabilitação (Nilsson et al., 2015). Alguns estudos revelam que as estratégias convencionais na reabilitação da DP não fazem a ligação entre as dimensões cognitiva e de planeamento (Intzandt et al., 2018), são caracterizados monótonos e desmotivadores e, consequentemente, levam a uma baixa adesão dos utentes ao tratamento (Ling et al., 2017). Tendo em conta estas limitações nos processos convencionais de reabilitação, os jogos como por exemplo os exergames, têm sido uma estratégia muito estudada na reabilitação do doente crónico (Dias et al., 2017). Este conceito de jogos eletrónicos envolve tarefas em ambientes virtuais onde o jogador é incentivado a atingir objetivos e a superar os limites durante os jogos (Ribas et al., 2017). Os exergames também são considerados como uma forma de 
exercício e têm sido implementados na reeducação da marcha e do equilíbrio nas pessoas com DP (Barry et al., 2014). Apesar de serem jogos onde frequentemente se simulam as atividades da vida diária, é consensual que o desempenho das tarefas pelo jogador não é equivalente ao desempenho na vida real (Medeiros et al., 2017), podendo não existir uma transferência direta do treino das atividades.

Contrariamente aos jogos eletrónicos, os Jogos Tradicionais Portugueses (JTP) aumentam o desempenho, o envolvimento e a integração social, bem como a aceitação do tratamento de reabilitação (Ling et al., 2017). Para além da componente social, os JTP promovem a coordenação motora, a lateralidade e o desenvolvimento do sentido rítmico (Coimbra, 2007). Os jogos tradicionais portugueses permitem ainda uma ligação intergeracional (Vaz et al., 2016), trazendo benefícios a ambas gerações, nomeadamente, aprendizagens interpessoais, transmissão de informações, altruísmo, desenvolvimento de habilidades sociais e coesão de grupo (Jones \& Herrick, 2004). No decorrer das atividades intergeracionais ocorrem algumas mudanças na atenção visual, na expressão facial, no desempenho e diálogo entre as gerações envolvidas (Morita \& Kobayashi, 2013).

Assim, considerando o potencial dos jogos tradicionais na reabilitação da pessoa com DP, este artigo tem como objetivo testar a aplicação de um programa de JTP adaptados, incluindo dinâmicas intergeracionais.

\section{Método}

\section{Participantes}

Neste estudo foi incluída uma amostra de conveniência constituída por universo de 34 pessoas com DP a frequentar um plano de reabilitação pela Associação de Doentes Parkinsónicos de Portugal. Foram incluídos todos os utentes com alguma capacidade para cumprir ordens simples e que concordassem em participar no estudo, fazendo-se acompanhar pelos respetivos cuidadores. Foram excluídos todos os utentes que apresentassem alguma condição cardiovascular grave que pudesse comprometer o seu desempenho $(n=12 ; 35,3 \%)$ - tendo por base as indicações técnicas da própria associação bem como a avaliação da equipa de investigadores - ou que não concordaram em participar $(n=13 ; 38,2 \%)$. Este momento de avaliação foi o primeiro contacto da equipa de investigadores com os participantes, não existindo nenhuma relação entre os intervenientes prévia ao estudo.

Para além das pessoas com DP e cuidadores, foi incluído no estudo um grupo de crianças do ensino pré-escolar Creche e Jardim de Infância - com 4,56 $\pm 0,53$ anos de idade, para participação numa sessão intergeracional com as pessoas com DP.

Após autorização ética para a realização deste estudo em comité especializado da Associação de Parkinson de Portugal, foi disponibilizada a informação detalhada sobre os procedimentos a todos os participantes capazes de consentir a sua participação, bem como aos cuidadores das pessoas com DP com alterações cognitivas, assim como os pais das respetivas crianças. Foi ainda solicitada a autorização para o registo e divulgação fotográfica do trabalho. A todos foi solicitada a assinatura do respetivo consentimento informado conforme Declaração de Helsínquia.

Dos nove participantes recrutados, um foi excluído por ter comparecido apenas à segunda sessão de JTP adaptados. Desta forma, foi considerado um total oito participantes com DP ( $N=8 ; 71,63 \pm 5,71$ anos de idade) incluídos no estudo. A maioria dos participantes $(n=6 ; 66,7 \%)$ apresentou alterações no seu estado cognitivo, conforme verificado nos registos da Associação de Parkinson Portugal através dos valores no Mini Exame de Estado Mental ajustados aos anos de escolaridade. Relativamente à independência na marcha, existiram três 
participantes com independência total (I), todos de género masculino (M), dois a depender de auxiliar de marcha (AM) e os restantes três a deambular em cadeira de rodas (CR) (Tabela 1). Assim, o grupo de participantes apresentou alguma heterogeneidade nas suas características cognitivas e motoras.

\section{Tabela 1}

Caracterização Individual dos Participantes com Doença de Parkinson

\begin{tabular}{lccccccccc}
\hline & \multicolumn{7}{c}{ Participantes com Doença de Parkinson } \\
\cline { 2 - 10 } & 1 & 2 & 3 & 4 & 5 & 6 & 7 & 8 \\
\hline Género & M & M & M & M & M & F & F & F \\
\hline Idade & 64 & 78 & 69 & 73 & 66 & 81 & 71 & 71 \\
\hline Independência da marcha & AM & I & I & I & CR & CR & CR & AM \\
\hline Cognição & C/A & S/A & S/A & C/A & C/A & C/A & C/A & C/A \\
\hline
\end{tabular}

Nota. $\mathrm{F}=$ Feminino; $\mathrm{M}=$ Masculino; $\mathrm{I}=$ Independente; $\mathrm{AM}=$ Auxiliar de Marcha; $\mathrm{CR}=$ Cadeira de Rodas; $\mathrm{S} / \mathrm{A}=\mathrm{Sem}$ Alterações ou Preservada; $\mathrm{C} / \mathrm{A}=$ Com Alterações.

\section{Instrumentos}

Escala de Autoeficácia (EA; Oliveira et al., 2016). A EA é um instrumento de medida com 10 itens, que visa avaliar o nível de confiança dos idosos para realizarem atividades com sentido, por si próprios, variando a sua pontuação entre 0 (não consigo de maneira nenhuma) e 10 (totalmente certo/a de que consigo) (Oliveira et al., 2016). A autoeficácia foi avaliada em todos os participantes e em todas as sessões no início e do fim de cada uma: Sessão 1 (início - T0; fim - T1); Sessão 2 (início - T2; fim - T3); Sessão 3/intergeracional (início - T4; fim - T5).

Entrevista estruturada a pessoas com DP e cuidadores. A entrevista foi dirigida às pessoas com DP e cuidadores em cada sessão, com o objetivo de compreender a perceção das pessoas sobre a importância dos jogos. As questões consideradas para a entrevista foram as seguintes: "O que achou desta sessão de jogos tradicionais?", "Voltaria a repetir?", "Qual o nível de dificuldade que sentiu?", "Se sentiu dificuldades, quais foram?", "Mudava alguma coisa nestes jogos?”, “O que acha que teve a trabalhar com os jogos?", "Aprendeu algo novo?”, "Algum destes jogos o fez recordar algo que conheça?”. A entrevista foi gravada em formato áudio, transcrita na totalidade e alguns campos foram assinalados/recortados no processo de transcrição, se associados com códigos da Classificação Internacional de Funcionalidade, Incapacidade e Saúde (CIF; Organização Mundial de Saúde [OMS], 2004).

Entrevista estruturada ao grupo de crianças. Durante a sessão educativa com as crianças, foram recolhidas informações de feedback das crianças, com o objetivo de caracterizar os conhecimentos e as aprendizagens retidas. Foi realizada uma entrevista semiestruturada no início e no fim da sessão educativa às crianças, incluindo algumas perguntas para compreender o nível do conhecimento geral sobre o tema do envelhecimento, nomeadamente: "Vocês têm avós ou bisavós?", "Vocês brincam com os avós e bisavós?", “Quais são as brincadeiras que fazem juntos?", "Vocês acham que eles têm dificuldades?", "Quais são as dificuldades que os vossos avós e bisavós têm?". No fim do teatro, foram novamente feitas algumas perguntas tais como: "Gostaram da história?”, “O que aprenderam hoje com este teatro?", "Acham que mesmo com dificuldades os avós e bisavós 
podem brincar convosco?", "Quando forem para casa, como é que iriam contar esta história aos vossos pais?", "Sentem-se mais preparados de ajudar um grupo de idosos?", com a finalidade de obter um feedback das crianças sobre as suas aprendizagens após a sessão educativa. A entrevista foi gravada em formato áudio, transcrita na totalidade e alguns campos foram assinalados/recortados no processo de transcrição, se associados com códigos da Classificação Internacional de Funcionalidade, Incapacidade e Saúde (CIF; OMS, 2004).

\section{Procedimentos Metodológicos}

Para a elaboração deste estudo, ocorreram três sessões em semanas consecutivas (uma sessão por semana) nos meses de dezembro de 2019 e janeiro de 2020, com implementação de jogos tradicionais portugueses adaptados à população-alvo, incluindo uma sessão intergeracional. Na terceira semana, foi realizada uma sessão educativa às crianças sobre o tema do envelhecimento, como preparação para a sessão de jogos intergeracional. Cada sessão teve uma duração de 45 minutos.

Os JTP implementados foram os seguintes: o jogo da malha, o jogo da colher, o jogo da cabra-cega e o jogo da macaca (Dias \& Mendes, 2013). Todas as regras dos jogos implementados foram adaptadas para a população-alvo (em função das suas características, grau de autonomia e funcionalidade).

O presente estudo teve como base uma metodologia mista de investigação, com recurso à recolha de dados qualitativa através de entrevista aos participantes e recolha de dados quantitativa, em relação ao nível de autoeficácia da pessoa com doença de Parkinson. No final de cada sessão dos JTP, alguns participantes, selecionados aleatoriamente, foram entrevistados individualmente. As entrevistas foram realizadas durante 17 a 43 minutos, com um tempo médio de entrevista de 30 minutos.

No início da sessão educativa dirigida às crianças foi realizada uma entrevista semiestruturada com a finalidade de caracterizar a sua perceção relativamente ao envelhecimento. A mesma entrevista foi repetida no fim da sessão.

\section{Primeira Sessão de Jogos Tradicionais Portugueses Adaptados}

Para esta primeira sessão, foram dinamizados o jogo da malha e o jogo da colher.

Jogo da Malha. O principal objetivo deste jogo era derrubar ou colocar a malha o mais próximo possível do alvo (Figura 1). As duas equipas foram compostas por quatro ou cinco elementos, sendo que cada equipa tinha pelo menos um membro a utilizar cadeira de rodas e dois com necessidade de apoio durante a marcha. Inicialmente, cada equipa escolhia uma cor (entre amarelo, azul e verde) que correspondia a pesos diferentes, com o objetivo de estimular memória e identificação das malhas durante o jogo. Cada jogador tinha de lançar pelo menos uma vez as três malhas de pesos diferentes.

As componentes adaptadas para este jogo foram as seguintes: (i) diminuição da distância entre o alvo e o ponto de lançamento; (ii) substituição das malhas por sacos de areia de diferentes cores e de diferentes pesos. 


\section{Figura 1}

\section{Jogo da Malha}

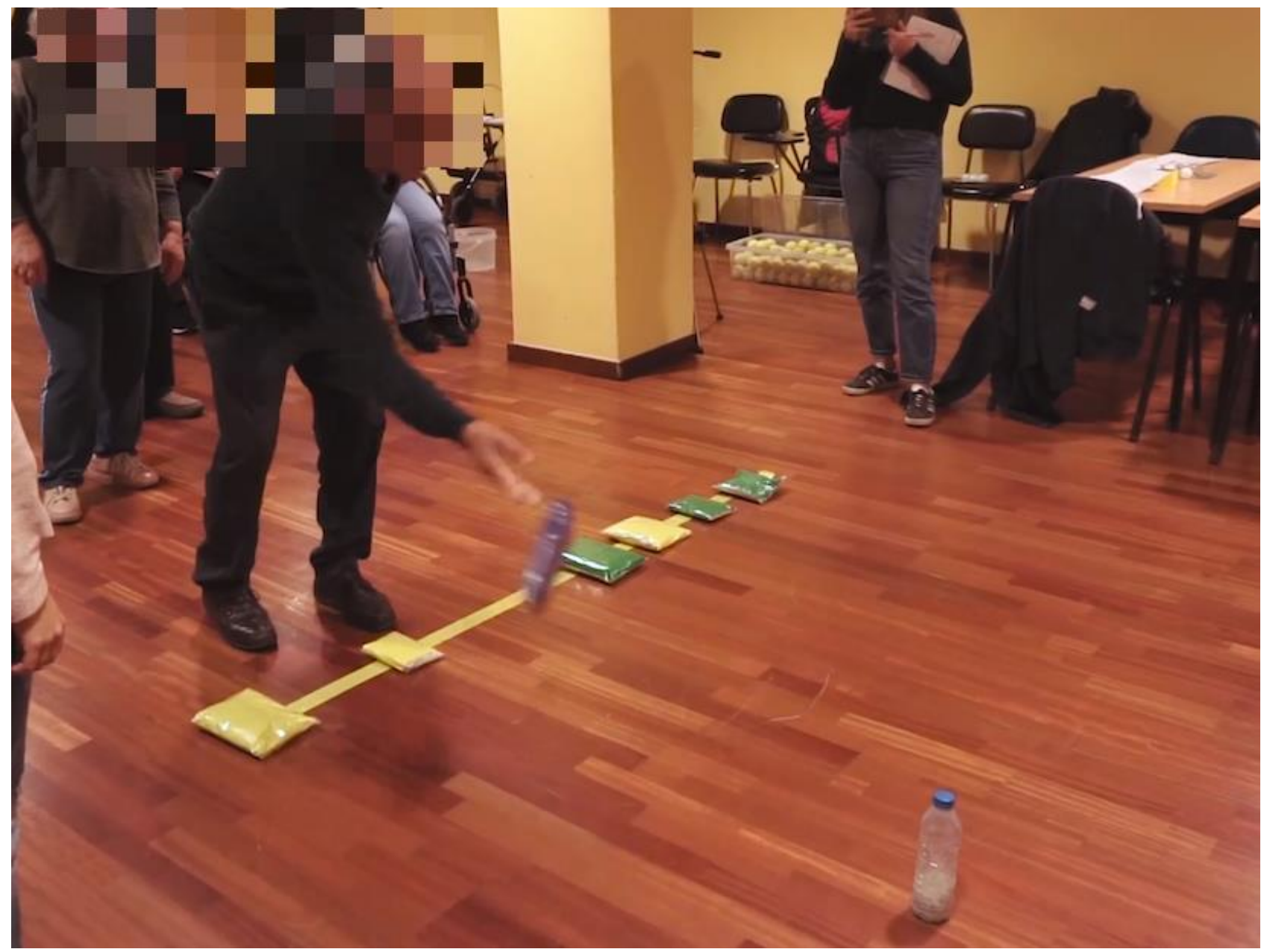

Jogo da Colher. O principal objetivo deste jogo era passar entre os participantes as seis colheres com uma bola de ping-pong em cada uma delas, sem deixar cair a bola, seguindo um ritmo determinado por batimento de palmas (Figura 2). Todos os participantes sentados foram organizados em círculo, tendo de passar uma colher com uma bola ao seu vizinho do lado direito. O sentido e o ritmo com palmas variavam cada vez que uma bola de ping-pong caía.

As componentes adaptadas para este jogo foram as seguintes: (i) o número de colheres introduzidas no jogo (potencialmente crescente); (ii) a textura das colheres: plástico e metal; (iii) a morfologia das colheres: colheres de sopa e colheres de sobremesa; (iiii) incorporação de ritmo com palmas. 


\section{Figura 2}

\section{Jogo da Colher}

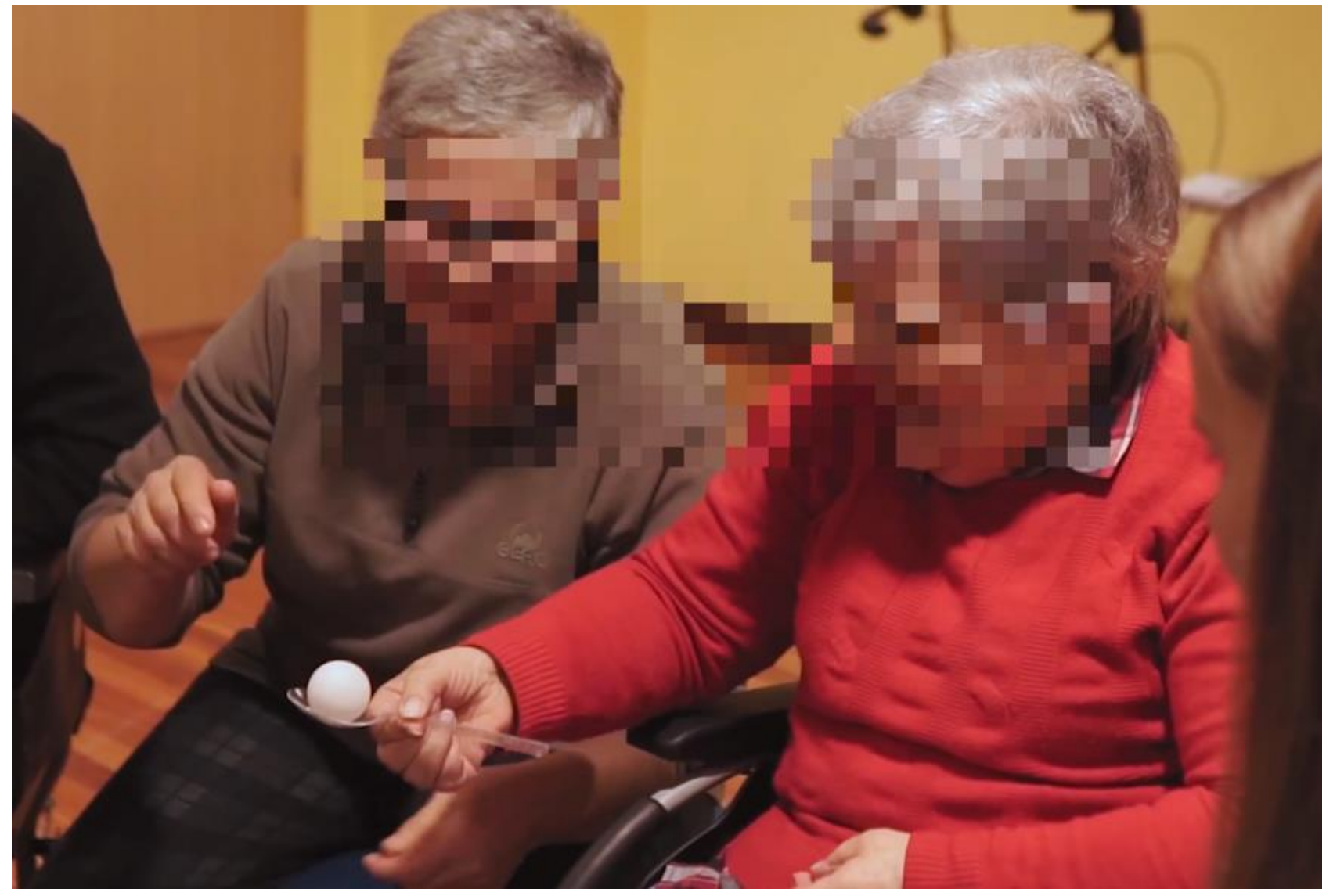

\section{Segunda Sessão de Jogos Tradicionais Portugueses Adaptados}

Para esta segunda sessão, foram efetuados o jogo da Cabra-cega e o jogo da Macaca.

Jogo da Cabra-cega. O principal objetivo deste jogo consistiu em identificar um objeto da vida diária através do tato e responder a algumas perguntas sobre a sua utilização (Figura 3). Todos os participantes permaneciam sentados e organizados em círculo, cada um com um objeto da vida diária (e.g., uma caneca, uma escova de pentear o cabelo, um garfo). Cada jogador vendado tinha obrigatoriamente um parceiro que o iria guiar com comandos simples (e.g., um passo em frente, virar à direita) até um participante com um objeto. A pessoa vendada tinha de identificar o objeto e responder a perguntas simples tais como: "De que cor é o objeto?", "Qual é a sua utilidade?", "Quando é que o utiliza?", "Demostre como o utiliza”.

As componentes adaptadas para este jogo foram: (i) a identificação e memorização das características de um objeto; (ii) a colaboração com um parceiro; (iii) execução de ordens simples; e (iv) resposta a perguntas sobre atividades da vida diária. 


\section{Figura 3}

\section{Jogo da Cabra-cega}

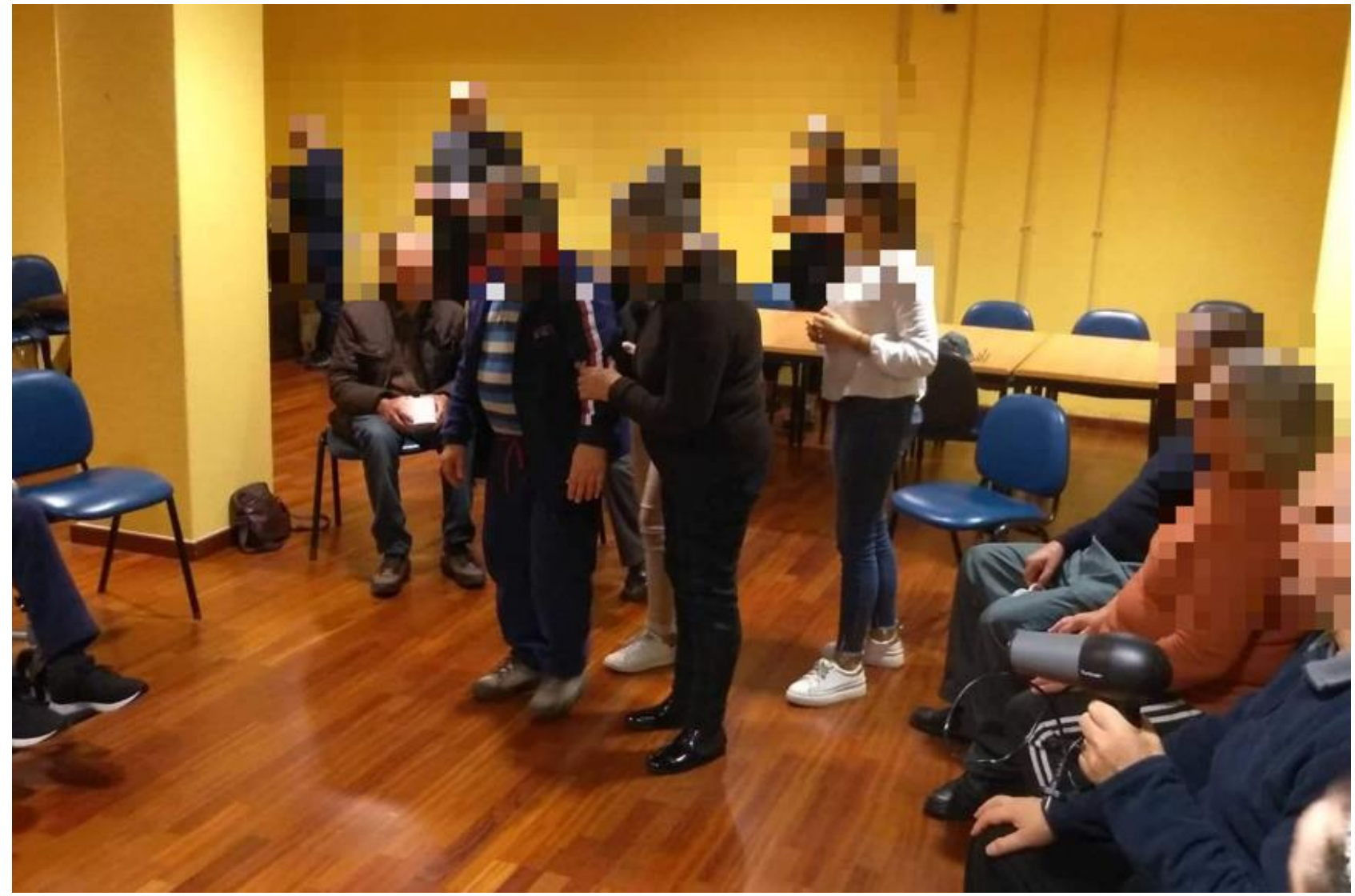

Jogo da Macaca. O principal objetivo deste jogo era percorrer a macaca com o seu respetivo parceiro respeitando o número de dribles de bola correspondente a cada cor da casa da macaca (Figura 4). Foram criadas duas "macacas" posicionadas lado a lado, cada uma com quatro cores diferentes de casas (vermelho, verde, azul e amarelo), repetidas duas vezes. Inicialmente, cada jogador tinha de escolher uma cor de uma malha (vermelha, azul, amarela ou verde), assim como o tamanho desejado $(0,5 \mathrm{Kg} ; 1 \mathrm{~kg})$ e lançá-la com para acertar na casa da cor correspondente. Após ter lançado as malhas, os jogadores não podiam colocar-se na casa onde se encontram as malhas. Desta forma, os jogadores teriam de observar a sua macaca, bem como, a macaca do seu par. Cada casa tinha um número que correspondia ao número de vezes que a bola teria de ser enviada entre os dois jogadores posicionados nas suas respetivas macacas.

As componentes adaptadas para este jogo foram as seguintes: (i) criação de duas macacas e trabalho em pares; (ii) inserção de cores nas casas para estimular a atenção permanente; (iii) incorporação de lançamento de uma bola para estimular a coordenação óculo-manual. 


\section{Figura 4}

Jogo da Macaca

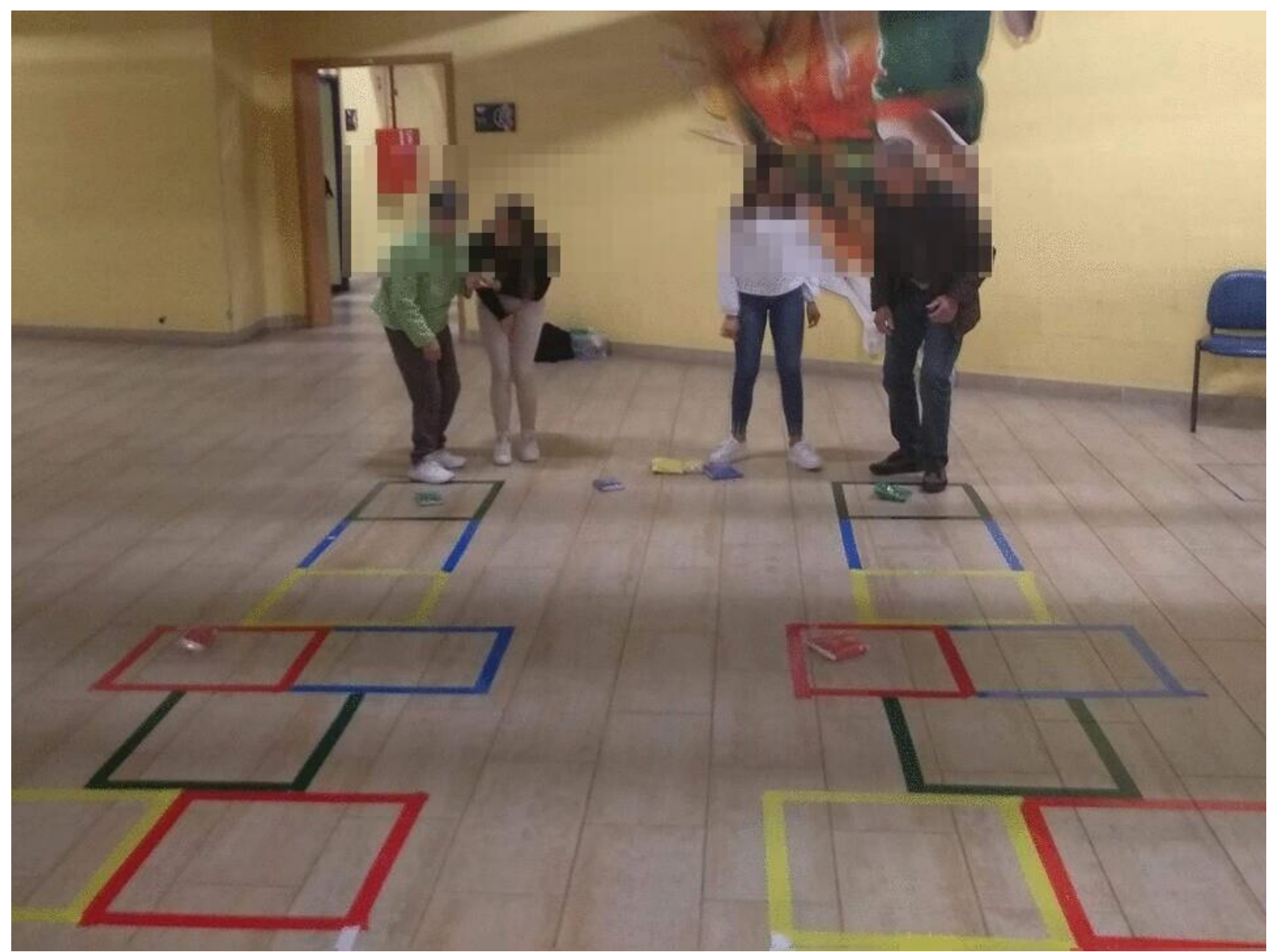

\section{Sessão Educativa para Preparação de Dinâmica Intergeracional}

Antes da terceira e última sessão com as pessoas com DP, ocorreu uma sessão educativa dirigida a crianças do ensino pré-escolar sobre o tema do envelhecimento. A sessão foi realizada através de uma peça de teatro com fantoches intitulada "Enquanto tu cresces ...", incluindo dinâmicas entre quatros personagens de uma família. Durante a sessão foram abordados conceitos tais como: a consciencialização e a educação das crianças relativamente ao envelhecimento, as dificuldades que advêm neste processo, a identificação do papel das crianças nesta fase da vida, assim como, a importância do jogo como uma estratégia intergeracional para o envelhecimento feliz. 
Por fim, cada criança obteve um crachá com o seu nome e o nome da pessoa com DP que iria ter como parceiro na sessão seguinte. Foi ainda explicado o papel de cada criança como dinamizadora e agente de suporte durante a sessão intergeracional com JTP.

\section{Terceira Sessão (Dinâmica Intergeracional)}

Inicialmente, cada criança identificou o seu parceiro com o objetivo de encontro e reconhecimento entre cada par de criança versus pessoa com DP. Posteriormente, dois grupos foram formados, um grupo realizar dedicado ao jogo da malha e o outro grupo dedicado ao jogo da macaca. Posteriormente, os dois grupos alternavam de jogo. No jogo da macaca, jogavam os pares: criança e pessoa com DP, com o objetivo de criar uma dinâmica de cooperação, bem como de entreajuda. Todos os participantes, incluindo pessoas com DP e crianças, realizaram exatamente as mesmas tarefas durante o jogo, nomeadamente: lançar a malha, identificar o número e a cor da casa, lançar a bola, deslocarem-se em simultâneo para as mesmas casas de jogo. Na presença de alguma dificuldade por parte de um dos parceiros de jogo, criança ou idoso, foi estimulada a cooperação entre jogadores. Durante esta sessão, o jogo da malha era igualmente jogado por pares. Cada elemento teve a oportunidade de lançar as 3 malhas pelo menos uma vez, cumprindo a ordem de lançamento acordada pelo par de jogadores, permitindo a comunicação e a colaboração entre ambos.

No final da terceira sessão, foi elaborada uma entrevista a alguns pares selecionados aleatoriamente, recolhendo informação sobre a sua experiência e participação nesta sessão intergeracional, incluindo as seguintes perguntas: "Gostaram de trabalhar em conjunto?", "Gostavam de repetir estes jogos com o/a seu/sua parceiro/a?", "Acharam difícil?", "Vocês ajudaram-se um/a ao outro/a?”, “O que aprenderam hoje com esta nova experiência?”, “O que gostaram mais de trabalhar em conjunto?", “Consideraram importantes estes jogos?".

\section{Procedimentos Analíticos}

Foram analisados os valores absolutos da escala de autoeficácia recolhidos antes e depois de cada sessão de JTP adaptados a pessoas com DP, assim como também foi considerada a diferença na autoeficácia entre T5-T0. Os dados recolhidos pelas entrevistas foram codificados com base nos códigos da Classificação Internacional de Funcionalidade, Incapacidade e Saúde (CIF) por dois investigadores independentes. Utilizou-se a codificação pela CIF por se tratar de uma ferramenta que estabelece uma linguagem comum para a descrição da saúde e dos estados relacionados com a saúde (OMS, 2004). Quaisquer conflitos na codificação foram discutidos e resolvidos com a intervenção de um terceiro investigador independente ao estudo e mais experiente.

Nas entrevistas realizadas às crianças antes e após a sessão educativa, foram comparados os conteúdos da CIF e analisadas as diferenças para interpretar o nível de aprendizagem obtido.

\section{Resultados}

\section{Os jogos tradicionais portugueses e o nível de autoeficácia da doença de Parkinson}

Relativamente à avaliação da autoeficácia dos participantes com DP, de uma forma geral, observou-se um aumento dos valores expressos antes e após cada sessão (Tabela 2). Assim, na primeira sessão, excluindo os valores máximos (10) reportados antes e mantidos após a sessão, todos os restantes participantes (P1, P3, P4 e P6) apresentaram um aumento de $50 \%$ dos valores da autoeficácia após a realização dos JTP adaptados. Houve 
uma outra exceção importante de um participante (P2) que apresentou uma ligeira diminuição na avaliação da autoeficácia, passando de 10 para 9 após realização das atividades. Posteriormente, na segunda sessão de jogos adaptados, 67\% das respostas dos participantes melhoraram (P1, P2, P3, P6 e P7), sendo que as restantes respostas (33\%) mantiveram o valor máximo de autoeficácia.

\section{Tabela 2}

Resultados Descritivos da Escala de Autoeficácia nas Sessões dos Jogos Tradicionais Adaptados

\begin{tabular}{|c|c|c|c|c|c|c|c|}
\hline \multirow{3}{*}{$\begin{array}{l}\text { Participantes } \\
\text { DP }\end{array}$} & \multicolumn{2}{|c|}{$\begin{array}{c}1^{\circ} \text { Sessão } \\
n=8\end{array}$} & \multicolumn{2}{|c|}{$\begin{array}{c}2^{\circ} \text { Sessão } \\
n=8\end{array}$} & \multicolumn{2}{|c|}{$\begin{array}{l}\text { Sessão Intergeracional } \\
\qquad n=16 \mathrm{a}\end{array}$} & \multirow{3}{*}{ T5-T0 } \\
\hline & Antes & Depois & Antes & Depois & Antes & Depois & \\
\hline & TO & $\mathrm{T} 1$ & $\mathrm{~T} 2$ & T3 & $\mathrm{T} 4$ & T5 & \\
\hline P1 & 3 & 4 & 5 & 6 & 10 & 8 & 5 \\
\hline P2 & 10 & 9 & 7 & 9 & 10 & 10 & 0 \\
\hline P3 & 5 & 10 & 8 & 9 & 8 & 10 & 5 \\
\hline P4 & 5 & 9 & 10 & 10 & 10 & 10 & 5 \\
\hline P5 & 10 & 10 & 10 & 10 & 10 & 10 & 0 \\
\hline P6 & 8 & 10 & 8 & 10 & 10 & 10 & 2 \\
\hline P7 & 10 & 10 & 8 & 10 & 10 & 10 & 0 \\
\hline P8 & 10 & 10 & 10 & 10 & 8 & 10 & 0 \\
\hline
\end{tabular}

Nota. DP = Doença de Parkinson. $\mathrm{P}=$ Participante. $\mathrm{T}=$ Momento de avaliação.

a Pares de crianças $(n=8)$ e dos participantes com DP $(n=8)$.

Na sessão intergeracional participaram oito crianças com os seus respetivos parceiros com DP. Para esta sessão, os resultados iniciais da autoeficácia foram superiores, comparativamente às duas sessões anteriores. As respostas referidas antes dos jogos por $63 \%$ dos pares, foram de cotação máxima da escala. Outros dois pares referiram melhorias na autoeficácia passando a atribuir o valor máximo da escala (Par 4, início - T4: 8 e fim T5: 10; Par 8, início - T4: 8 e fim - T5: 10). Ocorreu ainda uma ligeira diminuição na resposta de um par ( $\operatorname{Par} 1$ ), passando de 10 para 8, após realização da sessão. Por fim, a avaliação de T5-T0 permitiu perceber que todos os participantes mantiveram (Par 2; Par 5; Par 7; Par 8) ou melhoraram (Par 1; Par 3; Par 4; Par 6) a perceção do nível de autoeficácia ao longo das sessões de jogos tradicionais adaptados.

\section{Os jogos tradicionais portugueses - feedback de participação da pessoa com doença de Parkinson}

Pela análise das entrevistas no fim de cada sessão (Tabela 3), constatou-se que a maioria dos participantes com DP referiram que gostavam de repetir estas atividades, como podemos verificar através do exemplo do Participante 3: "Podíamos fazer isto mais vezes. Em vez dos exercícios de fisioterapia que são sempre iguais podíamos fazer jogos mais vezes." (b1264 - Abertura à experiência).

Numerosos códigos da CIF foram repetidos ao longo das três sessões elaboradas, nomeadamente: os jogos (d9200 - Jogos), a componente afetiva que advêm da experiência (b1522 - Amplitude da emoção), as memórias passadas (b1441 - Memória de longo prazo), a criação e a manutenção de relacionamentos entre os 
participantes e as crianças (d7502 - Relacionamentos informais com conhecidos; d730 - Relacionamento com estranhos).

Nas duas primeiras sessões, o feedback dos participantes focou-se essencialmente nas componentes desenvolvidas, por exemplo: "Trabalhei a memória, o psicológico, a destreza" (b144 - Funções da memória; d240 - Lidar com o stresse e outras exigências psicológicas; d440 - Utilização de movimentos finos da mão), "Estivemos a trabalhar a força dos braços a atirar a malha" (s73002 - Músculos do braço; b730 - Funções da força muscular; d4454 - Atirar), "Desenvolve a mente" (b164 - Funções cognitivas de nível superior), entre outras componentes.

\section{Tabela 3}

Excertos das Entrevistas aos Participantes (P) com DP, Cuidadores (Cd) e Crianças (Cr) nas Sessões dos Jogos Tradicionais Portugueses Adaptados

Sessões

Primeira sessão

Jogo da malha e Jogo da colher
Perceções após sessão

\section{Códigos da CIF}

P7 "Sim, gostei."
"Não foi difícil."
"Trabalhei a memória, o psicológico, a destreza."
"Jogava também ao Biltros ou vinte, que é parecido
ao que fizemos aqui."
"Aprendi a pensar mais e a memorizar."

b144 Funções da memória

b147 Funções psicomotoras

d240 Lidar com o stresse e outras exigências psicológicas

d440 Utilização de movimentos finos da mão

d449 Transportar, mover e manusear objetos, outros especificados e não especificados Pensar

d163 Amplitude da emoção b1522

Cd "Fez mexer os músculos dos braços." "Quando era garoto jogava muito à malha com os amigos. Foi engraçado jogar à malha aqui." "Foi interessante de como tínhamos de puxar pela cabeça para fazer os jogos e de nos mexer." "Foi muito divertido e é sempre bom termos momentos destes com as pessoas com os mesmos problemas que nós."

b780 Sensações relacionadas com os músculos e as funções do movimento

s73002 Músculos do braço

d920 Recreação e lazer

d9200 Jogos

b1522 Amplitude da emoção

e440 Atitudes individuais de prestadores de cuidados pessoais e assistentes pessoais

P3 "Gostei muito de jogar à malha e o jogo das colheres também foi muito engraçado."

"No primeiro jogo, apanhar a bola foi complicado, eram só bolas a fugir! Só nos riamos."

"Estivemos a trabalhar a força dos braços a atirar a malha. Trabalhamos as pernas a andar e a baixar-nos para apanhar as malhas. Trabalhamos também as mãos, o equilíbrio com as bolas e as colheres. $\mathrm{E}$ trabalhamos o cérebro com as cores e o tamanho das malhas."

"Quando era pequeno jogava muito à malha com os meus amigos, era o campeão! Jogávamos na terra, fazíamos campeonatos. Fez-me lembrar também outros jogos que jogávamos, como o peão, a apanhada e a macaca, na altura em que tinha energia d9200 Jogos b1522 Amplitude da emoção d3350 Produzir mensagens usando linguagem corporal

d4455 Apanhar

d4454 Atirar

s73002 Músculos do braço

b730 Funções da força muscular

d440 Utilização de movimentos finos da mão

d4105 Curvar-se

b1441 Memória de longo prazo

b260 Função propriocetiva

b1561 Percepção visual

d920 Recreação e lazer

d9205 Socialização para correr."

"Podíamos fazer isto mais vezes. Em vez dos exercícios de fisioterapia que são sempre iguais podíamos fazer jogos mais vezes." 


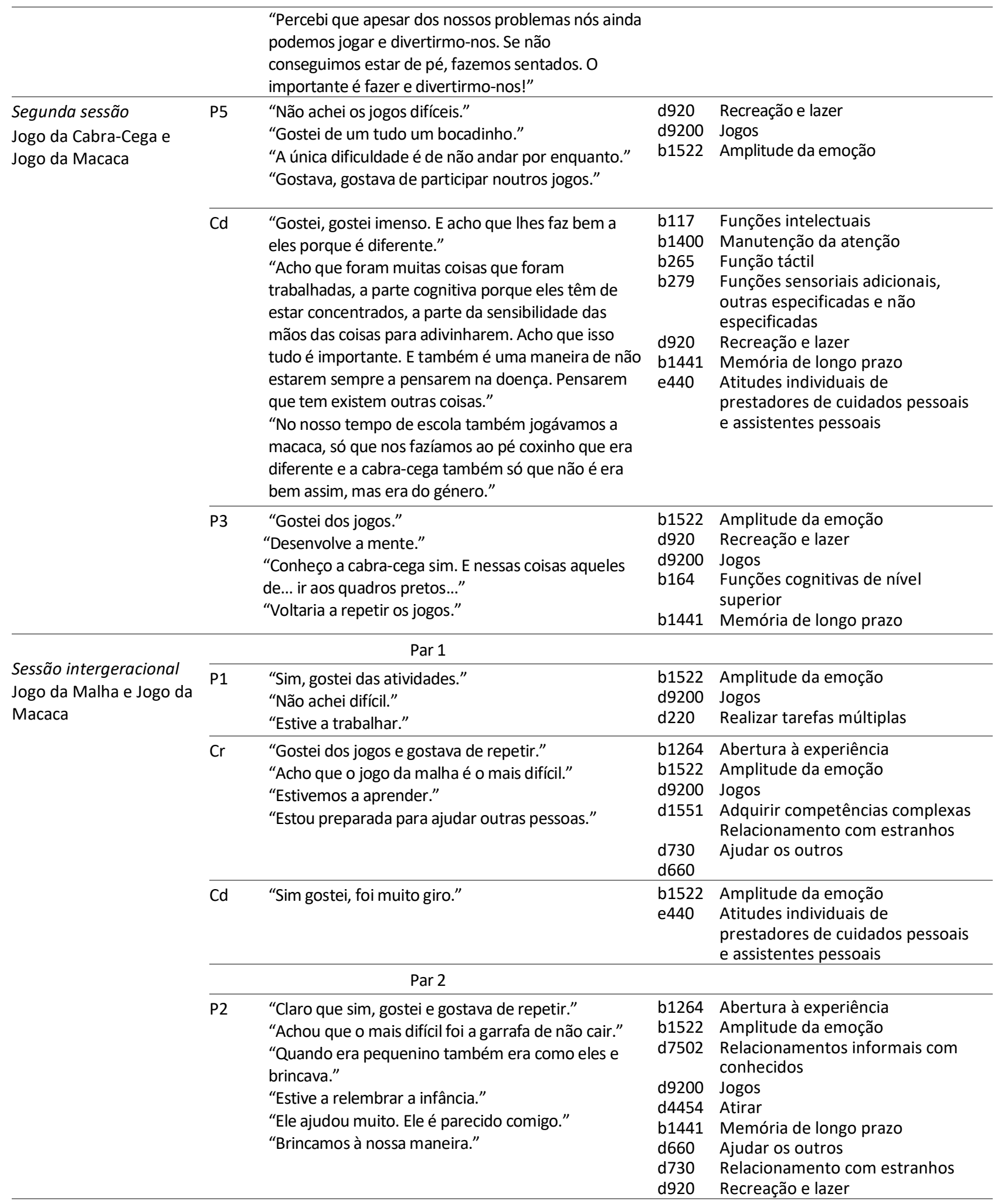


$\mathrm{Cr}$ "Sim gostei e gostava de repetir os jogos."

"Não achei difícil."

"Estive a ajudar."

"Sim, acho que mesmo com algumas dificuldades o senhor pode jogar a mesma. E os outros senhores que estão na cadeira de rodas ou que têm dificuldade a mexerem as mãos, também conseguem brincar a mesma."

"Eu brinco com os meus bisavós."

"Sim, sinto-me mais preparada para ajudar os meus avós e bisavós."

$$
\text { Par } 4
$$

P4 "Sim gostei e gostava de repetir."

"Não achei difícil."

"Estivemos a ajudar e a fazer exercícios".

"Sim senhora, acho que estes jogos e jogar com os meninos são importantes."

\begin{tabular}{l}
\hline Par 4 \\
\hline P4 "Sim gostei e gostava de repetir." \\
"Não achei difícil." \\
"Estivemos a ajudar e a fazer exercícios". \\
"Sim senhora, acho que estes jogos e jogar com os \\
meninos são importantes."
\end{tabular}

b1264 Abertura à experiência

b1522 Amplitude da emoção

d7502 Relacionamentos informais com conhecidos

d9200 Jogos

d660 Ajudar os outros

d175 Resolver problemas

d920 Recreação e lazer

d730 Relacionamento com estranhos

d7603 Relacionamentos com outros parentes b1264 Abertura à experiência

d7502 Relacionamentos informais com conhecidos

d299 Tarefas e exigências gerais, não especificadas

d9200 Jogos

d660 Ajudar os outros

d920 Recreação e lazer

d710 Interações interpessoais básicas

\begin{tabular}{|c|c|c|c|}
\hline $\mathrm{Cr}$ & $\begin{array}{l}\text { "Gostei e gostava de voltar a fazer os jogos." } \\
\text { "Não achei difícil." } \\
\text { "Estive a jogar." } \\
\text { "Sim, acho que os jogos e jogar com as pessoas com } \\
\text { dificuldades é importante." } \\
\text { "Sinto-me mais preparada para ajudar outras } \\
\text { pessoas e os meus avós e bisavós." }\end{array}$ & $\begin{array}{l}\text { b1264 } \\
\text { b1522 } \\
\text { d7502 }\end{array}$ & $\begin{array}{l}\text { Abertura à experiência } \\
\text { Amplitude da emoção } \\
\text { Relacionamentos informais com } \\
\text { conhecidos } \\
\text { Jogos } \\
\text { Recreação e lazer } \\
\text { Ajudar os outros }\end{array}$ \\
\hline \multicolumn{4}{|c|}{ Par 5} \\
\hline P5 & $\begin{array}{l}\text { "Eu gostei, claro gostei dos jogos e gostavas de } \\
\text { repetir." } \\
\text { "Para mim não, mas para eles que são mais } \\
\text { pequeninos é mais difícil." } \\
\text { "Tinha de ser outros jogos. Fazer os outros } \\
\text { parecidos." } \\
\text { "Aconselho fazerem jogos mais fáceis para as } \\
\text { crianças." } \\
\text { "Sinto-me capaz de ensinar aos meus netos para } \\
\text { brincar com eles a estes jogos." }\end{array}$ & $\begin{array}{l}\text { b1264 } \\
\text { b1522 } \\
d 7502 \\
\text { d9200 } \\
\text { b1403 } \\
\text { b1520 } \\
\text { b1262 } \\
\text { b1264 } \\
\text { d199 }\end{array}$ & $\begin{array}{l}\text { Abertura à experiência } \\
\text { Amplitude da emoção } \\
\text { Relacionamentos informais com } \\
\text { conhecidos } \\
\text { Jogos } \\
\text { Partilha da atenção } \\
\text { Adequação da emoção } \\
\text { Responsabilidade } \\
\text { Abertura à experiência } \\
\text { Aprendizagem e aplicação do } \\
\text { conhecimento, não especificadas }\end{array}$ \\
\hline $\mathrm{Cr}$ & $\begin{array}{l}\text { "Eu gostei das atividades e gostava de as repetir." } \\
\text { "Eu não achei os jogos difíceis." } \\
\text { "Fizemos jogos e ajudei." } \\
\text { "Em cadeira de rodas podia (6) fazer muitas coisas e } \\
\text { atirou (6) sacos". } \\
\text { "O senhor conseguiu apanhar a bola e fazer tudo } \\
\text { igual que eu." } \\
\text { "Sim, achei estes jogos muito importantes." }\end{array}$ & $\begin{array}{l}\text { b1264 } \\
\text { b1522 } \\
d 9200 \\
d 660 \\
\text { b152 } \\
d 4454 \\
d 4455 \\
\text { e445 }\end{array}$ & $\begin{array}{l}\text { Abertura à experiência } \\
\text { Amplitude da emoção } \\
\text { Jogos } \\
\text { Ajudar os outros } \\
\text { Funções emocionais } \\
\text { Atirar } \\
\text { Apanhar } \\
\text { Atitudes individuais de estranhos }\end{array}$ \\
\hline $\mathrm{Cd}$ & $\begin{array}{l}\text { "Ele (6) gosta muito de mudar." } \\
\text { "Era engraçado que quando era para ir buscar os } \\
\text { sacos, para ele escolhia o maior e dava a ele o mais } \\
\text { pequenino. É (C5) sensível, muito sensível." } \\
\text { "Eles tiveram muito divertidos." } \\
\text { "Nós sozinhos não fazemos nada, mas em equipa } \\
\text { conseguimos fazer muita coisa, somos ganhadores!" }\end{array}$ & e440 & $\begin{array}{l}\text { Atitudes individuais de } \\
\text { prestadores de cuidados pessoais } \\
\text { e assistentes pessoais } \\
\text { Atitudes individuais de } \\
\text { conhecidos, pares, colegas, } \\
\text { vizinhos e membros da } \\
\text { comunidade } \\
\text { Recreação e lazer }\end{array}$ \\
\hline
\end{tabular}


P6 meninos"

"Não, mas alguns jogos são difíceis, mas a menina

ajudou."

"Estivemos a trabalhar e fazer exercício."

"Andava sempre aos pulos quando era pequenina."

"Eu acho que a convivência entre pessoas doentes e crianças faz bem."

Cr "Gostei e gostava de repetir."

"Nada foi difícil."

"Gostei de ajudar."

"Aprendi o jogo da macaca com a senhora."

"Sim, é importante brincar com eles."
"Sim gostei e gostava de repetir os jogos com os

b1264 Abertura à experiência

b1522 Amplitude da emoção

d660 Ajudar os outros

d9200 Jogos

d220 Realizar tarefas múltiplas

b1441 Memória de longo prazo

e425 Atitudes individuais de conhecidos, pares, colegas, vizinhos e membros da comunidade

b1264 Abertura à experiência

b1522 Amplitude da emoção

d660 Ajudar os outros

d199 Aprendizagem e aplicação do conhecimento, não especificadas

Atitudes individuais de

e425 conhecidos, pares, colegas,

vizinhos e membros da

comunidade

Recreação e lazer

d920

\begin{tabular}{l} 
Par 8 \\
\hline P8 "Ela é muito bonita e tem uma avó com o mesmo \\
nome que eu." \\
"Acho, acho importantes estes jogos com as crianças." \\
"Sim. também é bom para ela (C8) porque aprendeu \\
coisas novas."
\end{tabular}

d159 Aprendizagem básica, outra especificada e não especificada

b1264 Abertura à experiência

b1522 Amplitude da emoção

d199 Aprendizagem e aplicação do

"O jogo da macaca já sabia, mas não assim e aprendi um novo jogo." conhecimento, não especificadas Recreação e lazer

importante."

d920 Atitudes individuais de

e425 conhecidos, pares, colegas,

vizinhos e membros da comunidade

Nota. ClF = Classificação Internacional de Funcionalidade, Incapacidade e Saúde.

\section{Os jogos tradicionais portugueses na doença de Parkinson e a intergeracionalidade}

Através da recolha do feedback das crianças após sessão educativa sobre o processo de envelhecimento, observou-se uma evolução ao nível da aprendizagem, pelo que foi percetível uma abordagem de diferentes componentes antes e após a sessão (Figura 5). Assim, antes da sessão, as crianças exploraram verbalmente três domínios relacionados com o envelhecimento, nomeadamente: o brincar (d920 Recreação e lazer), a mobilidade (d455 - Deslocar-se) e a comunidade (d910 - Vida comunitária), referindo as suas próprias experiências. No entanto, após a sessão, novos domínios surgiram, a referir: ajudar os outros (d660 - Ajudar os outros), aprender (d199 - Aprendizagem e aplicação do conhecimento, não especificadas) e jogar (d9200 Jogos).

As perceções obtidas no final da sessão intergeracional (Tabela 3) ficaram essencialmente centradas nas novas formas de interagir durante o jogo: “Aprendi o jogo da macaca com a senhora” (d199 - Aprendizagem e aplicação do conhecimento, não especificadas), na ajuda prestada ao outro: "Fizemos jogos e ajudei" (d660 Ajudar os outros) e, consequentemente, nas adaptações de atitudes da parte das crianças, como por exemplo 
uma cuidadora referiu "Era engraçado que quando era para ir buscar os sacos, para ele (criança) escolhia o maior e dava a ele (pessoa com DP) o mais pequenino "(e425 - Atitudes individuais de conhecidos, pares, colegas, vizinhos e membros da comunidade), bem como nas adaptações de atitudes das pessoas com DP: "Aconselho fazerem jogos mais fáceis para as crianças" (e425 - Atitudes individuais de conhecidos, pares, colegas, vizinhos e membros da comunidade). Os participantes com DP relataram com alguma frequência as suas memórias “Quando era pequeno jogava muito à malha com os meus amigos, era o campeão! Jogávamos na terra, fazíamos campeonatos. Fez-me lembrar também outros jogos que jogávamos, como o peão, a apanhada e a macaca, na altura em que tinha energia para correr" (b1441 - Memória de longo prazo); ou destacaram a importância da convivência entre diferentes gerações "Eu acho que a convivência entre pessoas doentes e crianças faz bem"(d710 - Interações interpessoais básicas) e a criação de novos relacionamentos informais "Sinto-me mais preparada para ajudar outras pessoas e os meus avós e bisavós" (d730 Relacionamento com estranhos).

\section{Figura 5}

\section{Evolução da Aprendizagem de Crianças Sobre o Processo de Envelhecimento Após Sessão Educativa}

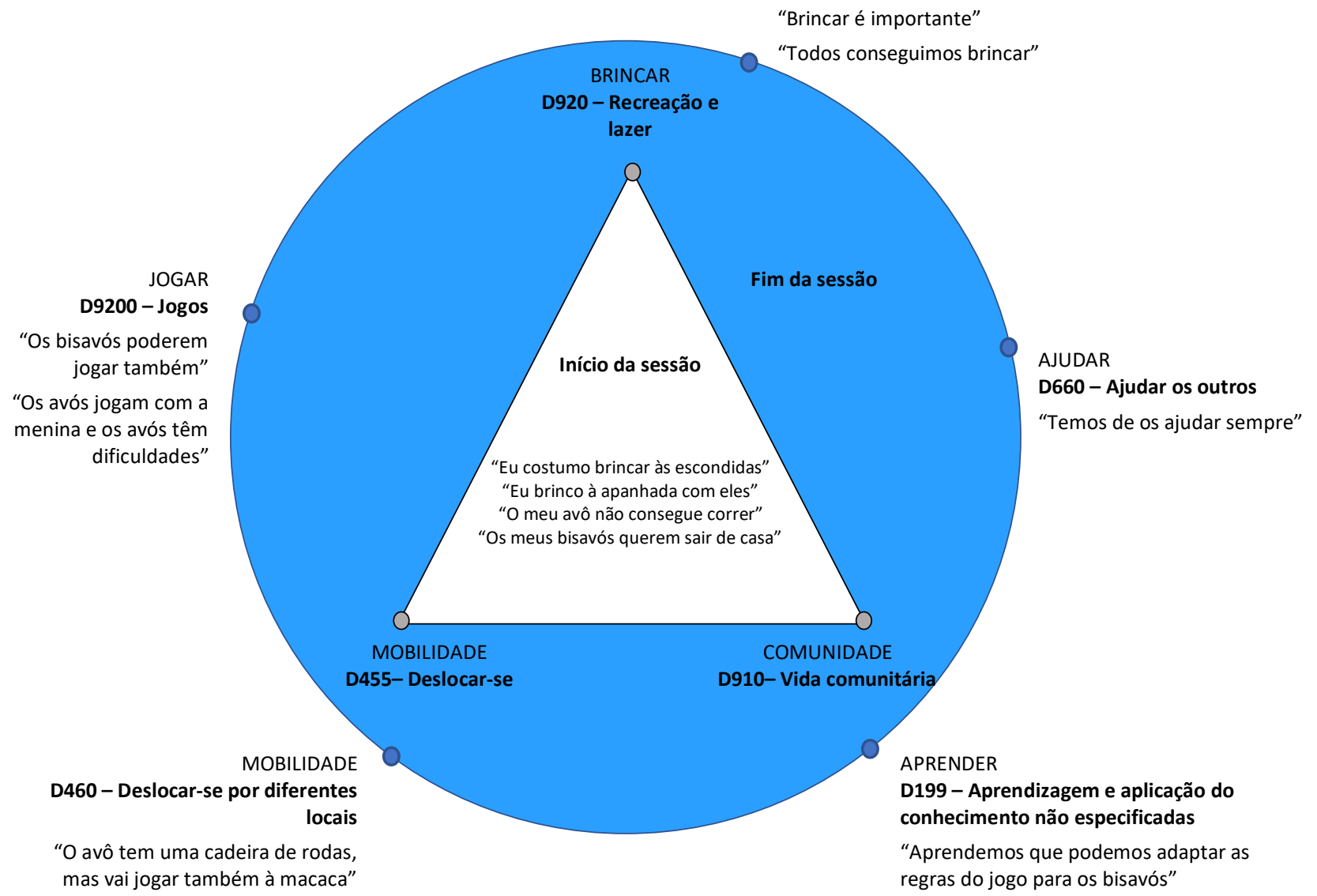

Nota. Domínios relacionados com o envelhecimento antes e após a sessão educativa. No interior do círculo estão os domínios antes da sessão e no exterior os domínios após a sessão educativa. 


\section{Discussão}

Este estudo apresenta os resultados da implementação de um programa de JTPA, incluindo dinâmicas intergeracionais, avaliando o seu impacto na autoeficácia da pessoa com DP e na perceção de experiências positivas. Os resultados ao nível de autoeficácia nas pessoas com DP demostraram uma evolução positiva entre o início e o fim da implementação dos JTP (T5-T0), verificando-se que 50\% dos participantes apresentaram melhorias e os restantes $50 \%$ mantiveram a cotação máxima na escala de autoeficácia ao longo do tempo. Após análise do nível de autoeficácia por sessão, é percetível que no fim da primeira sessão, $50 \%(n=4)$ dos participantes melhoraram e $37,5 \%(n=3)$ mantiveram a cotação máxima. No fim da segunda sessão de JTP, $62,5 \%(n=5)$ dos participantes melhoraram o seu nível de autoeficácia e os restantes $37,5 \%$ mantiveram $(n=3)$ a cotação máxima. O nível de autoeficácia resultante da implementação de jogos tem sido estudado essencialmente em outros contextos, nomeadamente em crianças, e sobretudo com recurso à implementação de jogos eletrónicos. Nestes estudos, a utilização dos jogos teve como objetivo melhorar o nível de autoeficácia relacionada com adesão à prática de atividade física e os resultados demonstraram uma melhoria significativa ao longo do tempo (Pakarinen et al., 2017; Santos et al., 2016), corroborando a importância de estratégias lúdicas como os jogos na melhoria da autoeficácia dos intervenientes.

As adaptações implementadas aos JTP tiveram como objetivo o estímulo cognitivo e sensorial, incluindo a utilização de, por exemplo, diferentes pesos e cores de malhas no jogo da malha. No processo de adaptação das regras, foi ainda tido em conta que os JTP implementados na população com DP não devem preconizar estratégias de pontuação, minimizando a competição e privilegiando a cooperação entre os participantes. As perceções dos cuidadores foram construtivas e enriquecedoras para a pesquisa, uma vez que referiram que os jogos implementados permitiram aos participantes perceber que têm muitas capacidades apesar do histórico e evolução da doença. Para além disso, os seus testemunhos indicaram que os jogos foram capazes de manter o caráter divertido enquanto se trabalhavam componentes importantes de um processo de reabilitação. Vários são os estudos anteriores referentes à implementação de jogos tradicionais, apesar de não se conhecer nenhum específico sobre a sua implementação na reabilitação de populações idosas de risco. Em estudo anterior, os autores Domberg et al. (2018) compararam o raciocínio das crianças durante jogos em contextos cooperativos e competitivos, e demostraram mais benefícios na evolução dos argumentos e na comunicação entre as crianças em contexto cooperativo, comparativamente ao contexto competitivo. Importa destacar que os jogos cooperativos estimulam a expressão de respeito, companheirismo, união e amizade (UNESCO, 2013), podendo ter resultados mais interessantes em contextos de reabilitação (Silva, 2014). Por outro lado, um outro estudo anterior envolvendo crianças e conduzido por Vasileva-Stojanovska et al. (2014), utilizou jogos tradicionais com temáticas específicas tais como a associação de competências matemáticas ao jogo da macaca, com vista a melhorar o raciocínio lógico; as competências artísticas para desenvolver habilidades expressivas; as habilidades sociais no jogo da apanhada com temas sobre a natureza/sociedade (Vasileva-Stojanovska et al., 2014). Neste estudo, alguns jogos foram adaptados de forma a reforçar as aprendizagens através de um sistema competitivo, em que cada criança teria pontos acumulados se terminasse com sucesso a sua jogada. Neste estudo em particular, esta estratégia funcionou como uma motivação para as crianças terem maior desempenho na atividade (VasilevaStojanovska et al., 2014). De facto, dependendo do objetivo pretendido, as dinâmicas criadas através da implementação de jogos, devem fazer uma adaptação consciente de regras competitivas ou colaborativas. 
No que diz a respeito à sessão intergeracional desenvolvida no presente estudo, inicialmente na avaliação da autoeficácia, 75\% das respostas reportadas pelos pares (criança e pessoa com DP) foram de imediato equivalentes à cotação máxima (10), o que não ocorreu durante as sessões de JTP. Assim, foi percetível um aumento do desempenho e da valorização do idoso nas atividades da sessão intergeracional, com melhoria da autoeficácia. A sessão intergeracional também teve um impacto essencial na perceção dos cuidadores, dado que muitos referiram que era mais benéfico para as pessoas com DP e para as crianças trabalhar em equipa, comparativamente ao trabalho individual. Vários estudos anteriores testaram o efeito de práticas intergeracionais, utilizando estratégias diferentes dos jogos tradicionais que foram utilizados no presente estudo. Um desses estudos implementou um programa intergeracional baseado em atividades psicomotoras, tendo por foco as habilidades sensoriais, motoras e sociais. Neste estudo foram avaliadas não apenas as perceções sobre as atividades elaboradas dos participantes como também dos profissionais de saúde, dos cuidadores, dos educadores de infância e dos pais (Mosor et al., 2019). Posto isto, a maioria dos participantes destacou que os cuidadores e educadores de infância deveriam estar presentes durante as sessões, por se considerarem pessoas de referência importantes para as crianças e adultos, ainda com o objetivo de garantir que os participantes se sintam à vontade e confiantes para a realização das atividades do programa intergeracional (Mosor et al., 2019). Um segundo estudo de Baker et al. (2017) implementou um programa intergeracional entre idosos com comprometimento cognitivo, deficits de memória, atenção e linguagem e estudantes de design. Durante 15 semanas cada idoso recebeu quatro visitas de 40 minutos com um grupo de alunos. Ao longo do processo e com a colaboração de ambas partes, estes identificaram uma necessidade do idoso e desde então os alunos criaram um produto a fim de complementar a necessidade do respetivo idoso. Assim, os resultados obtidos neste estudo revelam que os idosos estavam mais envolvidos nas atividades, sentiram-se mais valorizados e felizes durante as visitas dos alunos comparando com a ausência das visitas (Baker et al., 2017). Um outro estudo promoveu a cooperação entre idosos, cuidadores de crianças e crianças durante atividades lúdicas como jogos e atividades da vida diária como, por exemplo, fazer um bolo. Os resultados demonstraram níveis muito satisfatórios com a participação no programa, uma vez que o feedback retido nas entrevistas abordava temas como a experiência intergeracional, desenvolvimento pessoal, e a criação de relações de amizade (Skropeta et al., 2014). Considerando estudos anteriores sobre esta temática, os nossos resultados estão de acordo com a tendência já demonstrada em outras populações, por garantir que as dinâmicas intergeracionais diminuem o isolamento social, melhoram a autoavaliação da saúde física e psicológica dos idosos e permitem às crianças de fornecerem novas perceções sobre os idosos e as pessoas com doença (Cheng, 2016; Liang et al., 2014; Skropeta et al., 2014).

No presente estudo elaborado concluiu-se ainda que foi essencial educar e contextualizar as crianças sobre as condições da pessoa idosa, melhorando assim as suas perceções e atitudes em relação ao envelhecimento, pela referência a domínios como: ajudar os outros (d660 - Ajudar os outros), aprender (d199 - Aprendizagem e aplicação do conhecimento, não especificadas), jogar (d9200 - Jogos) e comunidade (d910 Vida - comunitária). Ainda na sessão conjunta foi percetível que as crianças e as pessoas com DP adaptaram as suas atitudes e transmitiram sentimentos de preocupação e atenção relativamente ao seu parceiro, havendo referências específicas: "Em cadeira de rodas o senhor podia fazer muitas coisas" e um participante relatou: "Para mim não, mas para eles que são mais pequeninos é mais difícil.". Num estudo anterior, onde se incluíram crianças de 3 a 11 anos e se descreveram as atitudes e as perceções que estas tinham sobre o processo de envelhecimento através das suas experiências (Gilbert \& Ricketts, 2008), os resultados revelaram que a maioria das crianças descreviam os idosos com características negativas e que a maioria do tempo passado com os idosos envolvia atividades 
passivas como ver televisão ou comer. Menos de um terço das crianças relatou realizar uma atividade para ajudar a pessoa idosa (Gilbert \& Ricketts, 2008). Outro estudo foi implementado focando-se na mudança de atitudes das crianças sobre o envelhecimento após realizações de atividades intergeracionais. Os resultados obtidos foram positivos uma vez que inúmeras crianças referiram que, após a experiência, o medo que sentiam relativamente ao contacto pessoal e de suporte com um idoso diminui e o sentimento de respeito e conforto aumentou. Posto isto, as crianças obtiveram uma opinião diferente sobre o envelhecimento e vêm o idoso ativo e altamente envolvido nas suas atividades diária (Aday et al., 1996). Desta forma, vários estudos afirmam que as perceções pejorativas das crianças bem como dos adultos sobre o processo de envelhecimento e os idosos vão-se aperfeiçoando com novas experiências vividas, por exemplo, no contexto de programas intergeracionais, que oferecem oportunidades para criar apoio mútuo e aumentar a familiaridade e a compreensão do processo (Aday et al., 1996; Duay \& Bryan, 2006).

Durante a implementação deste estudo foram várias as limitações metodológicas a considerar, nomeadamente, a duração (45 minutos) limitada de cada sessão, assim como a impossibilidade de se prolongar a continuidade do programa. Esta continuidade poderia ter permitido avaliar o impacto dos jogos na recuperação de parâmetros funcionais. É ainda de referir que a limitação na duração de cada sessão tornou impossível realizar as entrevistas à totalidade dos participantes no fim de cada sessão. Contudo, ao longo das três sessões foi possível entrevistar todos os participantes, pelo menos uma vez.

\section{Conclusão}

A implementação de JTP adaptados com inclusão de dinâmicas intergeracionais permitiu concluir sobre a validade da adaptação de JTP para pessoas com DP, o seu impacto na autoeficácia dos participantes e analisar as perceções das crianças, dos cuidadores e participantes relativamente às atividades. Os JTP permitiram a esta população uma melhoria da sua autoeficácia e uma perceção positiva e benéfica da participação nas atividades propostas. No autorrelato dos participantes durante a sessão intergeracional foi referido que aperfeiçoaram o trabalho da memória, desenvolveram habilidades motoras e cognitivas e aumentaram a sua interação social. Salienta-se ainda que a sessão educativa dinamizada com as crianças demonstrou um aumento nas dimensões percebidas sobre o envelhecimento, aumentando às dimensões da mobilidade, da comunidade e do brincar as dimensões de jogar, aprender e ajudar os outros, no fim da sessão. Os JTP demonstraram que são potenciais meios e estratégias de reabilitação na DP, devendo incluir dinâmicas intergeracionais. Futuros estudos nesta área devem implementar estes e outros jogos tradicionais adaptados em populações de risco com metodologias longitudinais e recolhendo a evolução consequente de parâmetros funcionais.

Agradecimentos | Acknowledgements: À Associação de Doentes Parkinsónicos de Portugal prestamos um agradecimento pela divulgação do estudo e da sua importância aos seus associados. Aos participantes no estudo e às suas famílias, agradecemos a sua disponibilidade, assiduidade e proatividade no programa de Jogos Tradicionais Portugueses implementado.

Conflito de interesses | Conflict of interest: nenhum | none.

Fontes de financiamento | Funding sources: nenhuma | none.

Contributos: MR: Desenho da metodologia; Tutoria e acompanhamento de recolha de dados; Revisões do trabalho. CGF: Recolha e análise de dados; Redação científica do trabalho. RA: Desenho da metodologia; Tutoria e acompanhamento de recolha de dados; Revisões do trabalho. TM: Recrutamento da amostra; Revisões da versão final. 


\section{Referências}

Aday, R. H., Aday, K. L., Arnold, J. L., \& Bendix, S. L. (1996). Changing children' s perceptions of the elderly: The effects of intergenerational contact. Gerontology \& Geriatrics Education, 16(3), 37-51. https://doi.org/10.1300/J021v16n03_04

Baker, J. R., Webster, L., Lynn, N., Rogers, J., \& Belcher, J. (2017). Intergenerational programs may be especially engaging for aged care residents with cognitive impairment: Findings from the avondale intergenerational design challenge. American Journal of Alzheimer's Disease and other Dementias, 32(4), $213-221$. https://doi.org/10.1177/1533317517703477

Barry, G., Galna, B., \& Rochester, L. (2014). The role of exergaming in Parkinson's disease rehabilitation: A systematic review of the evidence. Journal of NeuroEngineering and Rehabilitation, 11, Article 33. https://doi.org/10.1186/1743-0003-11-33

Cheng, S.-T. (2016). Self-perception of aging and satisfaction with children's support. Journal Educational Gerontology: Series B, 72(5), 782-791. https://doi.org/10.1093/geronb/gbv113

Coimbra, A. P. M. P. (2007). O papel dos jogos tradicionais como actividade lúdica e educacional [Monografia de Licenciatura, Universidade do Porto]. Repositório Aberto da Universidade do Porto. https://repositorioaberto.up.pt/bitstream/10216/14519/2/38185.pdf

Dias, G., \& Mendes, R. (2013). Jogos tradicionais portugueses. Edições Convite à Música.

Dias, S. B., Konstantinidis, E., Diniz, J. A., Bamidis, P., Charisis, V., Hadjidimitriou, S., Stadtschnitzer M., Fagerberg P., loakeimidis I., Dimitropoulos K., Grammalidis N., Hadjileontiadis, L. J. (2017). Serious games as a means for holistically supporting Parkinson's Disease patients: The i-PROGNOSIS personalized game suite framework [Apresentação de artigo]. 2017 9th International Conference on Virtual Worlds and Games for Serious Applications (VS-Games), Atenas, Grécia. https://doi.org/10.1109/VS-GAMES.2017.8056607

Domberg, A., Köymen, B., \& Tomasello, M. (2018). Children' s reasoning with peers in cooperative and competitive contexts. British Journal of Developmental Psychology, 36(1), 64-77. https://doi.org/10.1111/bjdp.12213

Duay, D. L., \& Bryan, V. C. (2006). Senior adults' perceptions of successful aging. Journal Educational Gerontology, 32(6), 423-445. https://doi.org/10.1080/03601270600685636

Gilbert, C. N., \& Ricketts, K. G. (2008). Children's attitudes toward older adults and aging: A synthesis of research. Educational Gerontology, 34(7), 570-588. https://doi.org/10.1080/03601270801900420

Intzandt, A. B., Beck, E. N., \& Silveira, C. R. A. (2018). The effects of exercise on cognition and gait in Parkinson's disease: A scoping review. Neuroscience and Biobehavioral Reviews, 95, $136-169$. https://doi.org/10.1016/j.neubiorev.2018.09.018

Jones, E. D., Herrick, C., \& York, R. F. (2004). An intergenerational group benefits both emotionally disturbed youth and older adults. Issues in Mental Health Nursing, 25(8), 753-767. https://doi.org/10.1080/01612840490506329

Kalia, L. V, \& Lang, A. E. (2015). Parkinson's disease. The Lancet, 386(9996), 896-912. https://doi.org/10.1016/S01406736(14)61393-3

Koerts, J., Beilen, M. Van, Tucha, O., Leenders, K. L., \& Brouwer, W. H. (2011). Executive functioning in daily life in Parkinson's disease: Initiative, planning and multi-task performance. PLoS One, 6(12), Artigo e292541. https://doi.org/10.1371/journal.pone.0029254

Liang, J., Zhang, P., Zhu, X., Qiao, Y., Zhao, L., He, Q., Zhang, L., \& Liang, Y. (2014). Effect of intergenerational and intragenerational support on perceived health of older adults: A population-based analysis in rural China. Family Practice, 31(2), 164-171. https://doi.org/10.1093/fampra/cmt073

Ling, Y., Meer, L. P. Ter, Yumak, Z., \& Veltkamp, R. C. (2017). Usability test of exercise games designed for rehabilitation of elderly patients after hip replacement surgery: Pilot study. JMIR Serious Games, 5(4), Artigo e19. https://doi.org/10.2196/games.7969

Medeiros, P., Capistrano, R., Zequinão, M. A., Beltrame, T. S., \& Cardoso, F. L. (2017). Exergames as a tool for the acquisition and development of motor skills and abilities: A systematic review. Revista Paulista de Pediatria, 35(4), 464-471. https://doi.org/10.1590/1984-0462/;2017;35;4;00013

Morita, K., \& Kobayashi, M. (2013). Interactive programs with preschool children bring smiles and conversation to older adults: Time-sampling study. BMC Geriatrics, 13. Artigo 111. https://doi.org/10.1186/1471-2318-13-111 
Mosor, E., Waldherr, K., Kjeken, I., Omara, M., Ritschl, V., Pinter-theiss, V., Smolen J., Hübel U., \& Stamm, T. (2019). An intergenerational program based on psycho-motor activity promotes well-being and interaction between preschool children and older adults: Results of a process and outcome evaluation study in Austria. BMC Public Health Volume, 19. Artigo 254. https://doi.org/10.1186/s12889-019-6572-0

Nilsson, M. H., Hagell, P., \& Iwarsson, S. (2015). Psychometric properties of the General Self-Efficacy Scale in Parkinson' s disease. Acta Neurologica Scandinavica, 132(2), 89-96. https://doi.org/10.1111/ane.12368

Oliveira, A., de Lima, M. P., \& Portugal, P. (2016). Escala de autoeficácia para a atividade com sentido: Encontrando sentido no envelhecimento ativo. Revista Portuguesa de Investigação Comportamental e Social, 2(1), 3-13. https://doi.org/10.7342/ismt.rpics.2016.2.1.28

Organização Mundial de Saúde. (2004). Classificação internacional de funcionalidade, incapacidade e saúde. https://catalogo.inr.pt/documents/11257/0/CIF+2004/4cdfad93-81d0-42de-b319-5b6b7a806eb2

Pakarinen, A., Parisod, H., Smed, J., \& Salanterä, S. (2017). Health game interventions to enhance physical activity selfefficacy of children: A quantitative systematic review. Journal of Advanced Nursing, 73(4), $794-811$. https://doi.org/10.1111/jan.13160

Ribas, C. G., Alves da Silva, L., Corrêa, M. R., Teive, H. G., \& Valderramas, S. (2017). Effectiveness of exergaming in improving functional balance, fatigue and quality of life in Parkinson's disease: A pilot randomized controlled trial. Parkinsonism and Related Disorders, 38, 13-18. https://doi.org/10.1016/j.parkreldis.2017.02.006

Robbins, T. W., \& Cools, R. (2014). Cognitive deficits in Parkinson's disease: A cognitive neuroscience perspective. Movement Disorders, 29(5), 597-607. https://doi.org/10.1002/mds.25853

Santos, H. Dos, Bredehoft, M. D., Gonzalez, F. M., \& Montgomery, S. (2016). Exercise video games and exercise selfefficacy in children. Global Pediatric Health, 3, 1-6. https://doi.org/10.1177/2333794X16644139

Silva, M. P. R. (2014). Jogos cooperativos e jogos competitivos na educaçâo física escolar [Monografia de Licenciatura, Centro Universitário de Brasília]. Repositório do Centro Universitário de Brasília. https://repositorio.uniceub.br/jspui/handle/235/5880

Skropeta, C. M., Colvin, A., \& Sladen, S. (2014). An evaluative study of the benefits of participating in intergenerational playgroups in aged care for older people. BMC Geriatrics, 14. Artigo 109. https://doi.org/10.1186/1471-2318-14-109

Vasileva-Stojanovska, T., Vasileva, M., Malinovski, T., \& Trajkovik, V. (2014, Outubro, 9-10). The educational prospects of traditional games as learning activities of modern students [Apresentação de artigo]. In C. Bush (Ed.), 8th European Conference on Game Based Learning, Berlin, Alemanha. https://bit.ly/3fQ0dSK

Vaz, J., Mendes, R., Dias, G., \& Santos, A. (2016). Jogos e brinquedos tradicionais portugueses: Análise intergeracional. In R. Mendes, G. Dias, J. Amado, \& O. Vasconcelos (Eds.), Jogos e brinquedos populares: tradição, património e legado (pp. 51-92). Escola Superior de Educação de Coimbra. 